\title{
The Effect of Degradation of Groundwater Resources On Capital of Pistachio Growers in Kerman Province
}

\author{
SEYED MOSTAFA MORTAZAVI, KARIM SOLAIMANI, ALI AKBAR MATKAN, \\ MAHMOOD HABIBNEJAD and MIR KHALEQ ZIA-TABAR AHMADI
}

\author{
'Department of Watershed Management, Sari University of Agricultural \\ Sciences and Natural Resources, Sari.
}

http://dx.doi.org/10.12944/CWE.9.3.45

(Received: July 16, 2014; Accepted: August 28, 2014)

\begin{abstract}
Real cost evaluation of water is necessary in agricultural products depending on obtained value by this input. In most areas of world especially in arid and semiarid areas, exist over pumping of ground water because the real value of water is much most than the costs of water supply and the lack of fit management water resources. In this study, using a sample of 110 farmers, water dealing value of over using of groundwater in Rafsanjan pistachio production area were investigated. Analysis and regression methods were used in this regard. The average determined value obtained 24 cents, for each share of water in this region which with over drafting of ground water, and decreasing quality and quantity of water has had significant relationship in the one percent significance level. Finally, for elimination or reduction of ground water degradation and its effects, this paper recommended in addition to reduction of licenses for ground water pumping. Determination of optimal economic water/land ratio in new and old pistachio producing areas is the other proposal of this research for alleviation groundwater over drafting effects. Permission for water conduction between wells and combination of fresh and saline water and also using desalination systems are methods for solving low quality of ground water.
\end{abstract}

Key words: Groundwater, Over-use, Dealing value of water, Rafsanjan plain.

\section{INTRODUCTION}

Today water is one of the most important factors in the growth and prosperity of human society (Ghasemzadeh et al. 2007). However, only one percent of the available water resources in the earth is drinking water that 98 percent of its is ground water (Jafari. 2008). In addition, $50 \%$ of the world's population supplies drinking water from ground water that this value is higher in Iran (Alizadeh, 2007). On the other hand, $65 \%$ of Iran is arid and semi-arid and the annual rainfall is less than $150 \mathrm{~mm}$ (Alizadeh, 2007). In addition, the spatial pattern of population in Iran is not compatible with the spatio-temporal pattern of water resources (Piroozi and Karzar, 2009). Nowadays, increasing the population and new technologies has led to overdraft of groundwater resources (Shahidasht and Abbasinejad, 2010). All these facts make the gap between supply and demand of groundwater which has led to ground water over use (Stanton and Fitzgerald, 2011). Gunn et al. (2011), by considering the ground water management in the world, concluded that ground water over use although made short-term benefits for the development of deprived or rural areas, but in the long-term leads to negative consequences for the environment.

Ackerman and Stanton (2011) investigated the water crisis in South-West of United states. Results showed that groundwater over use led to Reducing the quantity and quality of water and destruction of crops. Schrecongost et al. (2004) surveyed the water crisis in South-West of the United States and concluded that the negative consequences of ground water over use are due to poor water pricing scheme.

Jvanshah et al. (2003), Described the Characteristics of water demand and supply 
management in the Kerman province in Iran. They found that in this area, the only limitation is the complete destruction of water resources. The economic value of water is much higher than the cost of water harvesting. Barimnejad and Yazdani (2004) in a study tried to quantify the stability of water based on the economic theories. They mentioned that for modeling the sustainable management of water resources, at first it is necessary to define the relationship between water use and its consequences. So it is possible to consider water demand and supply according to present and future needs.

Therefore, in this study, to investigate these issues, Rafsanjan plain was chosen as the study area. This plain is in the arid and semi arid region which has $28 \%$ of Pistachio gardens in Iran But due to uncontrolled groundwater exploitation and lack of proper management, water resources is faced with many problems. The annual drop of ground water in the city has been $0.75 \mathrm{~m}$ per year (Kerman Regional Water Company, 2005). One of The consequences of uncontrolled exploitation in this region is that the trading price of water is reduced.

Jvanshah et al. (2005) has calculated the price of water in Rafsanjan. Also, Abdullahi (1996) presented the relationship between the reducing trading prices of water with increasing salinity of the water. It was mentioned that the price reduction is a reduction in capital. In this study, after computing the present value of each share of water, the water price function was estimated and in addition to the salinity, other variables due to excessive exploitation of groundwater are considered. Following this trend, one can predict the future state of capitals of Kerman Province pistachio farmers.

\section{Methodology}

In this study, two groups of data were used. The first group was Field statistics which were obtained by questionnaires. The second group of data was related to library information. In this context, previous studies including the results of Pistachio Research Institute (PRI) studies, books, scientific papers and theses of Master universities were used.
Field statistics required for this research were obtained using two-stage random sampling with 110 questionnaires. In this way, according to the water resources condition and the cultivation of pistachio, Rafsanjan and Anar cities were selected as the study area. For precise evaluation the plain of Anar and Rafsanjan divided to five regions including Rafsanjan, Anar, Noogh, Kashkooyeh and Kabootarkhan. Based on the number of wells in each region some wells were selected for study. Questionnaires were prepared for obtaining the desired characteristics of irrigation wells in the plain and filled by the operators of wells. In each of the five regions, eight percent of the irrigation wells were selected. Finally, a total of 110 questionnaires related to irrigation wells including 31, 27, 25, 20 and 7 samples belonging to Rafsanjan Anar, Noogh, Kabootarkhan and Kashkooyeh regions respectively. After specifying the studied wells, by referring to the operators of selected wells, several questions were asked about the characteristics of well and the gardens which irrigated by these wells. The questions were about The legal and factual discharge of wells, water salinity, drilling time and longevity of new wells, the total sales price of pistachio orchards under irrigation wells and the total area under cultivation. Finally, analysis of variance and regression analysis have done using SPSS.

To calculate the price reduction resulting from water over use, water price was considered as a function of the wells discharge, salinity, the life time of last drilled well and the area of gardens under irrigation. These functions were estimated using cross-sectional data collected from farmers. For a detailed investigation of the effects of salinity and its final effect on the price of each water share, a quadratic function was used. So the net effect of salinity on water price deflation was calculated.

\section{Study Area}

Rafsanjan plain is located in Dar Anjir desert catchment in Kerman province. Dar Anjir desert catchment is a part of Iran's central catchment. The plain covers an area of $12421 \mathrm{~km}^{2}$ with a wide range of altitudes from 3443 to $1400 \mathrm{~m}$. The area like a rectangle is drawn across the South East to North West. The Long-term average rainfall is $90 \mathrm{~mm}$ per year (Figure 1). Based on Demartonne classification it has a dry climate (Mortazavi et al., 2010). 
The average annual evaporation from the pan in this plain is more than $3000 \mathrm{~mm}$ (Mortazavi, 2008). The first and only current option for water supply in the plain is groundwater resources. The ground water passes the Rafsanjan and Kabootarkhan plains and divides into two parts. The first part moves to Anar and Kashkooyeh plains and finally flows to the basin outlet at Shoor river. The second part passes the eastern part of Rafsanjan and Kabootarkhan plains and move to Noogh plain. Finally this part flows to Bafgh wetland in Yazd province. (Jvanshah et al., 2005). Figure 2 shows the study area.

\section{RESULTS}

First, for better understand of the problem, the characteristics of rinse well in Rafsanjan

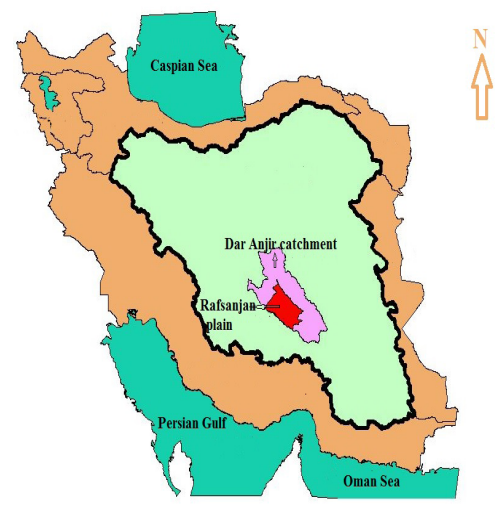

Fig. 1: Boundary of the study area in Iran plain presented in table 1 and compared with other studies. Table 1 shows that the real average discharge of wells is 23.28 liters per second, while the average statutory discharge of wells is $\mathbf{2 5 . 4 2}$ liters per second. It indicates that the real pumping discharge is less than statutory discharge. The real average discharge of wells in Abdolahi (1996), Javanshah (2003) and Javanshah et al. (2005) were $29.87,27.54$ and 23.19 respectively. The legal rate of pumping in Abdullahi (1996) and Jvanshah et. al (2005) studies were 25.43 and 31.14 respectively.

Table 1 shows that the average of salinity of groundwater in Rafsanjan is 7209 . This value was 6070 in 1996 (Abdullahi, 1996). It indicates that, the quality of the water resources of the region reduced during the study periods. On the average, the last well drilling in Rafsanjan was in 1998. So the new well life is 13.44 year. Each irrigation well on average covers 95 hectares of pistachio orchards which was 108 hectares in Jvanshah et al. (2003) study. In other words, it can be said that due to lack of water, the covering pistachio gardens of each irrigation well has decreased. Row 7 of Table 1 show that the dealing value of each cubic meter of water in Rafsanjan plain is 0.33 dollar.

For a more detailed review of Rafsanjan Plain aquifer properties, the plain has been divided into smaller regions and each of the variables in Table 1 were evaluated in separate areas. The results are given in Table 2. As table 2 shows, the actual discharge of wells in Rafsanjan, Noogh and
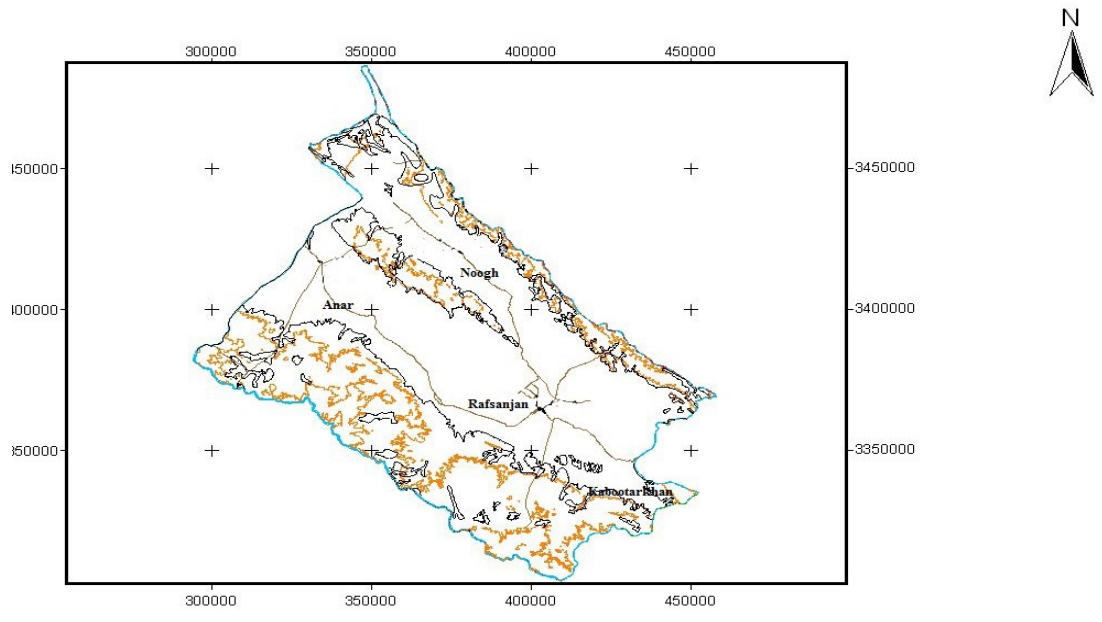

Fig. 2: Boundary of the Rafsanjan plain 
Kashkooyeh are 19.61, 21.83 and 18.05 respectively which there is no significant difference between them.

For Anar and Kabootarkhan the actual discharge is 28.04 and 26.05 respectively. There is no significant difference between these two regions. However, the difference between these two regions and the other regions is significant at $10 \%$ level. This is while in the statutory wells discharge, only Noogh is different from other at $1 \%$ level significance. In other words, the average statutory discharge in Noogh is 18.5 liters per second which is the lowest among the regions. In other areas, these values vary in the range of 24 to 29 liters per second, which is not significantly different from each other. Statutory discharge values in Rafsanjan, Anar, Kashkooyeh and Kabotarkhan are 27.02, 29.96, 26.37 and 24.78 liters per second respectively. As it is clear, from the moment the only real discharge more than legal discharge is for Noogh. In other words, the water management is not in compliance with the needs and capacities.

According to table 2, these regions can be divided into three categories based on water salinity (Ec). Ground water salinity of Anar is much higher than other areas. The average salinity of wells in Anar is 11446.3 . Ground water salinity in Kashkooyeh and Noogh areas is less than Anar and higher than the other two regions. The average Ec of these two regions are 6471.4 and 6236.5 respectively. The third group is Kabootarkhan and Rafsanjan. The average Ec of these two regions are 5515.8 and 5482.66 respectively.

Table. 1: The average value of different variables of Rafsanjan plain wells and comparison of the results with other studies. 1996, 2003, 2005 and 2011 refers to Abdullahi (1996), Javanshah et al. (2003), Javanshah et al. (2005) and this study findings

\begin{tabular}{llcccc}
\hline & Variable & $\mathbf{1 9 9 6}$ & $\mathbf{2 0 0 3}$ & $\mathbf{2 0 0 5}$ & $\mathbf{2 0 1 1}$ \\
\hline 1 & Real well discharge (lit/s) & 29.87 & 27.54 & 23.19 & 23.28 \\
2 & Statutory well discharge (lit/s) & 25.43 & & 31.14 & 25.42 \\
3 & Water salinity & 6070 & & & 7209 \\
4 & The last year of well construction & & & 1374 & 1376.5 \\
5 & The life time of last drilled well (year) & & \multirow{2}{*}{108.65} & & 13.44 \\
6 & Pistachio garden area (hectare) & & & 2200 & 7326.53 \\
7 & Dealing value of one cubic meter (dollar) & & & & \\
\hline
\end{tabular}

Table. 2: The average value of different variables of five regions wells. ${ }^{*},{ }^{* *},{ }^{* * *}$ shows 1,5 and 10 percent of significance level respectively

\begin{tabular}{|c|c|c|c|c|c|c|}
\hline Variable & Rafsanjan & Anar & Noogh & Kabootarkhan & Kashkooyeh & F statistics \\
\hline 1 Real well discharge (lit/s) & 19.61 & 28.04 & 21.83 & 26.05 & 18.5 & $2.43^{\star}$ \\
\hline $\begin{array}{l}2 \text { Statutory well } \\
\text { discharge (lit/s) }\end{array}$ & 27.02 & 29.96 & 18.5 & 26.37 & 24.78 & $4.95^{\star \star \star}$ \\
\hline 3 Water salinity & 5482.66 & 11446.3 & 6236.54 & 5515.79 & 6471.43 & $16.24^{\star \star \star}$ \\
\hline $\begin{array}{l}4 \text { The last year of well } \\
\text { construction }\end{array}$ & 1374.6 & 1370.74 & 1382.77 & 1377.61 & 1381.71 & $4.26^{\star \star \star}$ \\
\hline $\begin{array}{l}5 \text { The life time of last drilled } \\
\text { well (year) }\end{array}$ & 15.4 & 19.26 & 7.23 & 12.4 & 8.28 & $4.26^{\star * *}$ \\
\hline $\begin{array}{l}6 \text { Pistachio garden area } \\
\text { (hectare) }\end{array}$ & 82.65 & 118.7 & 83.46 & 111.42 & 55.71 & $3.83^{* *}$ \\
\hline $\begin{array}{l}7 \text { Dealing value of one cubic } \\
\text { meter (dollar) }\end{array}$ & 5249.02 & 10607.8 & 7490.46 & 5966.34 & 6599.66 & $2.55^{\star \star}$ \\
\hline
\end{tabular}


The latest well position shifting was in Noogh and Kashkooyeh (in 2003) that shows the difference with other regions in $1 \%$ significance level. The maximum life time of new wells is 19 years in Anar. Also table two shows the comparison of average Gardens area belonging to each well in these five areas. The wells in Kashkooyeh irrigates in average 55.71 hectares of gardens while this is 82.65 and 83.46 hectares for Rafsanjan and Noogh respectively. Also in Anar and Kabootarkhan each well irrigates 118.7 and 11.42 hectares of gardens respectively. Based on table two, 1 cubic meter of water in Anar costs 0.33 dollars which is different from the others areas in 5\% significant level. This value is $0.17,0.25,0.2$ and 0.22 dollars in Rafsanjan, Noogh, Kabootarkhan and Kashkooyeh respectively. The reason of higher price in Anar will be discussed in the next sections.

The impact of water quality and quantity on dealing value of water, Dealing value of water is a function of the actual well discharge, the life time of last drilled well, the total irrigated gardens and water salinity. This function is illustrated by the following regression equation.

$$
\begin{gathered}
p s w=8.485 \times 10^{7}+1.701 \times 10^{8} \times(\mathrm{An}) \\
+825.507 \times\left(\mathrm{Ec} \times \mathrm{AB}_{\mathrm{v}}\right)+2265113.014 \\
\times\left(\mathrm{OR}_{\mathrm{J}}\right)+712782.05 \times(\mathrm{A})-1980.729 \times(\mathrm{Ec})
\end{gathered}
$$

PSW: dealing value of water in dollar

An: Anar area

$B_{v}$ : real discharge of well (lit/s)

$\mathrm{OR}_{\mathrm{J}}$ : the life time of the last drilled well

A: total irrigated gardens area (hectare)

Ec: water salinity $(\mu \mathrm{S} / \mathrm{cm})$

This Function with 99\% confidence level shows that, the $51 \%$ of the sales value per share of water in Rafsanjan is depend on the interaction between salinity and water consumption, lifetime of last well constructed, entire orchards irrigated per well and water salinity. Equation 1 shows that, by increasing the interaction between salinity and discharge of each well, the water dealing value per share has increased. In other words, in Rafsanjan, the wells that have more discharge have the highest salt content. So the dealing value of water per share is more in these cases. Reducing the discharge of wells and thus reduce salt per liter of water, the water value of water decreases 2.75 cents per liter.

Decreasing every year of the life time of last drilled well, the purchase and sale of water shares have reduced eighty dollars. Indeed, the increase in annual losses, the frequency of well shift will increase which lead to decreasing of life time of last drilled well. Finally, by reducing the life time of the last well, the dealing value per share will decrease. Water dealing value per share has reduced 0.73 dollar by increasing one salinity. These three variables indicate that reducing well discharge and water quality lead to decreasing value of water. Since the main capital of farmers is the water resources which is available for them, reducing the water resources lead to decreasing their capital.

With increasing each hectare of garden to the total area which irrigates by each well, the dealing value per share of the water has increased 23.77 dollar due to the more restrictions on water resources. In Anar, dealing value per one hour water is 5666 dollars higher than in other regions because the well lifetime in this region is more than the other regions (Table 2). Also in this region the total area irrigated per well is more compared to other regions (row 6, Table 2). So in this area, water resources limitation is more sensible and dealing value per share is higher than any other regions.

For a more detailed examination of the effects of salinity on the dealing value of each share of water, another function was established. This function is illustrated by the following regression equation.

$$
\begin{gathered}
p s w=-7.313 \times 10^{7}+239995.798 \times(\mathrm{Ec})^{2} \\
+3386499.72 \times\left(\mathrm{OR}_{\mathrm{J}}\right)+1146337.467 \\
\times(\mathrm{A})+1.747 \times 10_{8} \times(\mathrm{An})
\end{gathered}
$$

The variables are the same as equation 1.

This function with $99 \%$ confidence level shows that $38 \%$ of the dealing value per share of water in Rafsanjan depends on water salinity, the quadratic function of salinity, the life time of last well and total irrigated gardens area per well. 
In this function, despite the quadratic variable of salinity, salinity variable has a positive coefficient and the quadratic factor is negative.

To calculate the marginal effects of salinity on water prices, the following formula should be used.

$$
p s w=23996-2.414 \times(\mathrm{EC})
$$

As the above formula shows, the salinity of 9940 , has no effect on the value of water. In salinities higher than 9940 , with salinity increasing, water price will be decreased. Considering that the average salinity in Rafsanjan is 7209 , salinization of water will not reduce the dealing price. However by taking the average salinity in Anar (11446) into account, increasing water salinity, leads to decreasing dealing price in this area. Reduced price due to a decline in the quality is loss of capital.

\section{CONCLUSION}

The average salinity of groundwater in Rafsanjan is 7209 . Comparative study of salinity in Abdullahi (1375) study and this study shows a trend in water resources quality in Rafsanjan plain. The five areas of Rafsanjan plain, based on water salinity (Ec) were divided into three categories. The first group is Anar with higher salinity than other areas. Noogh and Kashkooyeh areas are in the second group in terms of salinity while Rafsanjan and Kabootarkhan have the best quality of water among all which are in the third group.

Real average discharge of wells is 23.28 liters per second. However, the average statutory discharge of wells is 25.42 liters per second. Given that irrigation wells license renewals and replacements are not consistent with annual rainfall, and due to lower real discharge than the allowable discharge, Control based on the amount of allowable discharges to prevent the destruction of the aquifer is not useful. These results are consistent with Jvanshah et al. (2005) findings. In addition, the actual discharge obtained in this study compared to the Abdullahi (1996), Jvanshah et al. (2003) and Jvanshah et al (2005) findings shows a decreasing trend. It is shown that groundwater aquifer in Rafsanjan plain is running out. The statutory discharge which obtained in this study is consistent with Abdullahi (1996) and Jvanshah et al (2005) findings.

The results showed that the actual legal discharge in four areas in Rafsanjan and Anar are significantly different. The lowest discharge is for Kashkooyeh wells. Due to lower real discharge than the allowable, it shows that this is due to water shortages in the region. The most discharge is for Anar and Kabootarkhan. However, in these areas the actual discharge is less than the allowable. Only in Noogh the real discharge is higher than the legal discharge. Meanwhile, the average statutory discharge in Noogh is less than other areas. In other words, the management of water resources is not consistent with the needs and capacities of different areas and this result can be considered to have violated the law and the provisions of the excessive exploitation of groundwater resources. It should be noted that other areas lack of water also leads to water overuse. The minimum difference between legal and real discharge belongs to Anar and Kabootarkhan. Water resources condition in Kabootarkhan is better than other regions in Rafsanjan plain.

Wells on average irrigates 95 hectares of pistachio orchards. Comparing this value with Jvanshah et al. (2003) study shows a trend of reduced areas of orchards per well. In other words, due to water shortages, areas under pistachio gardens were reduced. These five areas can be divided into three groups based on the average surface covered by irrigated gardens. The first group includes Kashkooyeh wells which cover the least pistachio orchards. Minimum real discharge of wells belongs to this area wells. In other words, it is due to dehydration and loss of some gardens. Noogh and Rafsanjan areas are in the second group while Anar and Kabootarkhan are in the third group which the real discharge is the most among these areas.

Dealing value per cubic meter of water in Rafsanjan plain is 24 cents. Increasing in annual loss and thereby reduce of wells discharge, decreasing the life time of last drilled well as well as water quality decreases, causes the water value decrease. With increasing each hectare to the total area of irrigated gardens, the dealing value per share of the water will increase due to more restrictions on water resources. 
In Anar, dealing value per share is more than other areas. It is due to the fact that the last well lifetime and the total area irrigated per well, compared to other regions are more in this area. So in this area, water resources limitation is more sensible and dealing value per share is higher than any other regions.

According to the results based on the function of the dealing value of each share of water, water with 9940 salinity has the highest economic value. Considering that the average salinity in Rafsanjan is 7209 , the increasing salinity of the water will not decrease the dealing price. However by taking the average salinity in Anar (11446) into account, increasing water salinity will decrease the dealing price in the region. Reducing price due to a decline in the water quality is capital loss.

Given devaluation of the wealth of farmers due to Uncontrolled water exploitation, estimating the social value of water is recommended. In other words, in economic evaluation, not only considering the private benefits and costs but also social costs and benefits should be considered. This will decrease the amount of water use from the aquifer.

According to the results based on the water price function, the water with 9000 salinity is the best water for pistachio cultivation. Therefore, the mixing of fresh and salt water will have the most efficiency. So it is suggested that irrigation department issued a permit to transfer water between irrigation wells to provide possible mixing of water by farmers. Also it is possible to use brackish water desalination systems. Regards (2011) also mentioned that in areas with limited infrastructure and high water demand using water desalination systems can provide selfsufficiency.

Considering that the average amount of actual water use from underground aquifers is less than issued license and water level drops continue yet, it is suggested that the statutory discharge decrease gradually.

\section{REFERENCES}

1. Rafsanjan plain Studies. Kerman Regional Water Corporation, Rafsanjan Office of Water Resources Studies. P.P. 350 (2005).

2. Barinnejad, V., Yazdani, V.S., Sustainability analysis in water resources management in the agricultural. Research and development journal. 63: 2-16 (2004).

3. Piroozi, K.R., Karzar, R., Water resource economics (supply and demand). National Conference on Sustainable Development patterns in water management (2009).

4. Jafari, M., Restoration of arid regions. Tehran university press. P.P. 247 (2008).

5. Javanshah, A., Salehi, V.F., Abdulahi, M., Prioritization of irrigation methods and techniques in order to provide the most economical agricultural water resources in pistachio orchards of Kerman province. Pistachio Research Institute of Interior project (2003).

6. Javanshah, A., Abdulahi, M., Sedaghati, N., Hosseini-Fard, S.J., Mahmodi-Meymand, S., Mohammadi Mohammad Abadi, A., Salehi, V.F., Economic and Social Survey of the possibility of using water desalination units in pistachio orchards of Rafsanjan. Pistachio Research Institute of Interior project (2005).

7. Shahi-Dasht, A., Abbasnejad, A., Management of water resources, challenges and solutions (case study: Kerman province). Fourth International Congress of the Islamic World Geographers (2010).

8. Abdulahi, M., The role of policy coordination in pistachio cultivation unsustainable development with emphasis on water resources. Journal of Agricultural and Development Economics. 63: 117-137 (2008).

9. Abdulahi, M., Economic evaluation of agricultural water supply options in Rafsanjan. Master thesis in economics, university of Shiraz (1996).

10. Alizadeh, A., Principles of Applied Hydrology. Quds Razavi Institution Press. P.P. 807 (2007).

11. Ghasemzadeh, M., Mohammadi, B., Kazemi, M., Traditional and new forms of social and economic evaluation of structural and 
biological operations to protect soil and water resources (Case Study - Shahid Yaghuobi Dam basin, Khorasan Razavi province). Sixth Conference of Agricultural Economics (2007).

12. Mortazavi, S.M., Assessing the Consequences of excessive groundwater withdrawal in Rafsanjan plain. Watershed management Master's thesis, University of Mazandaran (2007).

13. Mortazavi, S.M., Solaimani, Karim, Ghafari, F., Water Resources Management and Sustainable Development. Case Study: Rafsanjan plain. Technical report (2010).

14. Ackerman, F. and Stanton, E.A., "The Last Drop: Climate Change and the Southwest Water Crisis". Somerville, MA: Stockholm Environment Institute-U.S. Center, Available at http://seius.org/publications/id/371 (2011).

15. Gunn. E. L, M.R. Llamas, A. Garrido, D. Sanz.
, "Groundwater Management", Treatise on Water Science, Chapter1.07, Pages 97-127 (2011).

16. Rygaard, m., P. J. Binning, H.J. Albrechtsen. "Increasing urban water self-sufficiency: New era, new challenges". Journal of Environmental Management, 92((2011)): 185-194 (2011)

17. Schrecongost.a. J, Staatz, B, Diallo, and M.Yade. "Water Pricing as Tool for Itegrated Water Resource Mnagement": A synthesis of Key Issues for Rural Weet Africa. Bureau for Economic Growth, Agriculture \& Trade. Number 73 (2004).

18. Stanton, Elizabeth A. and Ellen Fitzgerald . California Water Supply and Demand: Technical Report. Somerville, MA: Stockholm Environment Institute-U.S. Center. Available online at http://sei-us.org/publications/id/369 (2011). 